\title{
Parametric Optimization of Orthotropic Girders in a Cable-Supported Bridge
}

\author{
Baandrup, Mads Jacob; Poulsen, Peter Noe; Olesen, John Forbes; Polk, Henrik
}

Published in:

Journal of Bridge Engineering

Link to article, DOI:

10.1061/(ASCE)BE.1943-5592.0001499

Publication date:

2019

Document Version

Peer reviewed version

Link back to DTU Orbit

\section{Citation (APA):}

Baandrup, M. J., Poulsen, P. N., Olesen, J. F., \& Polk, H. (2019). Parametric Optimization of Orthotropic Girders in a Cable-Supported Bridge. Journal of Bridge Engineering, 24(12), [04019118].

https://doi.org/10.1061/(ASCE)BE.1943-5592.0001499

\section{General rights}

Copyright and moral rights for the publications made accessible in the public portal are retained by the authors and/or other copyright owners and it is a condition of accessing publications that users recognise and abide by the legal requirements associated with these rights.

- Users may download and print one copy of any publication from the public portal for the purpose of private study or research.

- You may not further distribute the material or use it for any profit-making activity or commercial gain

- You may freely distribute the URL identifying the publication in the public portal 


\title{
Parametric Optimization of Orthotropic Girders in a Cable Supported Bridge
}

\author{
Mads Baandrup ${ }^{1}$, Peter Noe Poulsen ${ }^{2}$, John Forbes Olesen ${ }^{3}$, and Henrik Polk ${ }^{4}$ \\ ${ }^{1}$ DTU Civil Engineering, Technical University of Denmark, 2800 Kgs. Lyngby, Denmark. Email: \\ mjba@byg.dtu.dk; COWI A/S, Department of Major Bridges International, 2800 Kgs. Lyngby, \\ Denmark \\ ${ }^{2}$ DTU Civil Engineering, Technical University of Denmark, 2800 Kgs. Lyngby, Denmark \\ ${ }^{3}$ DTU Civil Engineering, Technical University of Denmark, 2800 Kgs. Lyngby, Denmark \\ ${ }^{4}$ COWI A/S, Department of Major Bridges International, 2800 Kgs. Lyngby, Denmark
}

\begin{abstract}
In the last six decades closed-box orthotropic steel girders have been widely used in cable supported bridges. Several parametric studies were previously carried out in order to reduce inherent fatigue stress problems and in general to improve the bridge girder designs. However, in most cases, only one or two parameters were studied simultaneously, hence the full potential of orthotropic girders is not achieved. In the present work, a multi-scale FE model of a suspension bridge is established with sophisticated boundary conditions applied to a local parametric sub-model of a bridge girder. With this local model an automated gradient-based parametric optimization is carried out with the goal of minimizing weight or price of the girder. It is thus possible to optimize several design variables simultaneously, and concurrently fulfilling constraint functions on fatigue stresses, deformation and buckling. The results show potential weight savings of 6-14\% and price savings of $9-17 \%$, mainly found by thinner plates and narrower troughs. Besides the explicit savings, the results indicate the potential of applying gradient-based optimization in civil engineering designs.
\end{abstract}




\section{INTRODUCTION}

Since the 1960s (Wolchuk and Harris 1959) the orthotropic steel girder design has been of great use in large cable supported bridges. The design concept has proven to have many advantages compared to the alternative of using truss girders, but also many challenges have arisen during the past six decades, where in particular fatigue problems have been in focus (Wolchuk 1990; Fisher and Dexter 1997). During these years, the design concept of the closed steel box with orthotropic plates has been under continuous development, and has been subject to extensive research in the search of a more optimal design (Wolchuk 1999). The search for an optimized design is continued in this work where a gradient-based approach is applied in a parametric optimization of the usual design variables.

Previously, several parametric studies of orthotropic decks have been completed. In (Oh et al. 2011), and followed up by (Oh and Bae 2013), a parametric study of the influence of the crossbeam height, thickness and shear area, and deck plate thickness with focus on fatigue stresses in the cut-out around troughs has been carried out. The main findings are that increasing height, thickness and shear area of the cross-beam is able to reduce the maximum stresses, whereas the thickness of the deck plate is not closely related to the stresses in the cut-out. Similarly, the influence of the cut-out geometry on stresses at the trough-to-diaphragm connections has been studied in (Connor 2004). Here a parametric study of certain variables in the cut-out has shown that the recommendations in the 2002 AASHTO LRFD Bridge Design Specifications produce increased stresses in fatigue-sensitive regions. Furthermore, several other parametric studies have recently been conducted in (De Backer et al. 2006), (De Corte and Van Bogaert 2007), (De Corte 2009), (Tang 2011), (Fettahoglu 2015), and (Fettahoglu 2016) where all of these works showed possible improvements to the orthotropic steel deck.

A common feature of all the above works, is that only one or two design parameters are studied at a time. Such an approach is very similar to the usual design process carried out by engineers when designing orthotropic steel girders, which is a natural consequence of the increasing complexity arising when several design parameters are changed simultaneously. The sum of effects and 
consequences on e.g. stresses in fatigue details and structural stiffness is often too complex to comprehend. Thus it is of great interest to study the effect on the design when optimizing multiple design variables simultaneously, which is possible when applying automatic gradientbased optimization methods. Previous examples of gradient-based parametric optimization are seen in (Mrsa and Medic 1996), (Peng et al. 2005), and (Ding et al. 2010).

In the present work, a gradient-based parametric optimization of an orthotropic bridge girder in a cable supported bridge has been conducted. The basis of the optimization is the 2,682 $\mathrm{m}$ long Osman Gazi Bridge opened in July 2016 in Turkey. The aims of the study are mainly to optimize the design parameters of the bridge girder and subsequently to identify trends in the various design variables leading to more optimal structures. A tertiary goal is to prove the concept and possibilities of applying gradient-based optimization in the design of large civil engineering structures, e.g. cable supported bridges.

The model subjected to optimization is a single section of a closed orthotropic steel bridge girder, where the usual design parameters of the top deck are defined as design variables. The basis of the optimization is a suitable finite element model, where the detail level varies from coarse discretized orthotropic shell and beam elements, to a finer discretized shell model from where fatigue stresses are calculated.

Since only a single section of the entire bridge girder is modeled, attention must be given to ensuring acceptable boundary conditions to this local model. To ensure correct stiffness along the boundaries of this single section model a multi-scale model has been established. Hence, a global beam/shell model of the entire cable supported bridge has been modeled, and subsequently analyzed for each load case. Afterwards, displacement fields from this global model have been applied to the boundary of the local model, onto which the optimization has been performed subsequently. This method reduces the model size in the optimization, but ensures the correct stiffness along the boundaries of the local model.

The gradient-based parametric optimization is carried out within an optimization framework developed for the present study. Two independent objective functions have been defined as weight 
or price minimization. The choice of design variables (plate thicknesses, diaphragm distance, trough geometry etc.) and constraints (fatigue, deformation, and buckling) may be varied and combined as desired by the user.

The implemented optimization framework and FE model have been used in nine different optimization cases. In the first eight cases the objective is minimization of the weight, whereas in the last case the objective is minimization of price. The main focus has been on weight minimization, as the weight is a clear and unambiguous measure, and due to the general goal of reducing girder weight in cable supported bridges. In the first three cases the complexity is increased from a single free design variable to ten free design variables. In the following five load cases different lower boundaries for plate thicknesses are studied together with a variation in constraint functions. Finally, the effect of minimizing price is compared to the results from minimization of weight.

\section{METHODS}

The basis for the optimization framework is the general non-linear inequality constrained optimization problem given as

$$
\begin{array}{ll}
\min _{\mathbf{x} \in \mathbb{R}^{n}} & f(\mathbf{x}) \\
\text { s.t. } & c_{j}(\mathbf{x}) \leq 0, \quad j=1 \ldots m \\
& l b_{i} \leq x_{i} \leq u b_{i}, \quad i=1 \ldots n
\end{array}
$$

where $f(\mathbf{x})$ is the non-linear objective function, $c_{j}(\mathbf{x})$ are the non-linear constraint functions, and $\mathbf{x}$ the design variable vector. Each design variable $x_{i}$ has lower $l b_{i}$ and upper $u b_{i}$ bounds. In the following the different elements of the general optimization problem (1) will be defined and tied to the actual optimization problem being solved.

An optimization framework has been developed to facilitate the gradient-based parametric optimization of the bridge girder. The flowchart seen in Figure 1 shows a general overview of the framework, which consists of two main parts; (a) the optimization environment itself and (b) the studied finite element model (bold enhancement). 
The optimization environment has been implemented in MatLab (MATLAB 2016) and the problem was solved with the non-linear solver Knitro from Artelys (Byrd et al. 2006), applying the sequential quadratic programming (SQP) algorithm. The optimization algorithm is gradient-based, but as several of the constraint functions were based on the finite element model, no analytical gradients were available. The gradients of the objective and constraint functions with respect to the design variables were thus computed numerically by the finite difference method. The design variables, objective and constraint functions, and stability check are all described in detail in the last part of this section.

The local finite element model, which served as the basis for constraint functions and stability check, was modeled in the commercial software Abaqus (Abaqus 2016). The model was scripted in Python (Nagar 2018) to allow for altering design variables, and to allow it to be called from the Matlaв optimization framework. The local model was of a single section of a bridge girder, with dimensions based on the detailed design of the Osman Gazi Bridge (Turkey). The Osman Gazi Bridge was designed by COWI A/S and when opened to traffic in July 2016, possessed the world's fourth longest main span of 1,550 $\mathrm{m}$ and a total length of 2,682 $\mathrm{m}$. It is thus a state-of-art design within large cable supported bridges. The bridge deck is a closed steel mono-box girder with orthotropic deck and truss diaphragms. The FE model is described in detail in the following subsection.

Despite the study being based on a specific bridge, the results of the study in regard to trends and correlations between the various design parameters are considered to be generally valid. However, the exact results with respect to minimization of weight and price are only valid for the specific bridge, whereas the methods are generally applicable.

\section{Finite Element Model}

The optimization only focused on the top part of the girder, as many challenges often arise when designing this part. Hence, only local effects (such as fatigue, local deformation, and buckling) were included in the optimization problem. The basis for the optimization was thus a local finite element model of a single section of the bridge girder, which furthermore reduced the problem size 
handled during the iterative optimization process.

This local model was an individual FE model, but posed as a lower level in a multi-scale model, which was established to ensure correct boundary conditions to the local model. This multi-scale model, detail levels of the local model, and the boundary conditions on the local model are described in the following.

\section{Multi-scale Model}

When reducing a continuous deck girder to a local model of only one section, special attention must be given to the boundary conditions of this section. The solution to this challenge was to establish a multi-scale model and utilize the Abaqus "sub-model" feature. A schematic overview of the multi-scale model with main dimensions and terminology of sub-levels is seen in Figure 2.

The multi-scale model consists of two models with different detail levels, respectively a global and a local model. The global model was mainly made from beam elements, but with five sections (in total $125 \mathrm{~m}$ ) of the bridge girder replaced by a orthotropic shell/beam elements (see (Andersen and Hansen 2012) and (Bjærre 2015) for details). The orthotropic shells were introduced to reduce a complete shell model consisting of top plate and troughs to a single shell element with stiffness properties equivalent to the complete model. Similarly, beam parts in the diaphragms were reduced to orthotropic beam elements with equivalent stiffness properties. This method of model reduction was previously proven applicable in (Bjærre 2015).

The local model corresponds to the center section of the global orthotropic shell elements. Detail levels of this model are described in the following subsection.

The global model was solely used to calculate admissible boundary conditions for the local model, hence not included in the optimization itself. The principles applied for determining the boundary conditions on the local model are described in the subsequent subsection. The material applied to the entire multi-scale model was steel with elasticity modulus $E=210 \mathrm{GPa}$ and Poisson's ratio $v=0.3$.

\section{Detail Levels of Local Model}

The local model was established with two detail levels as shown in Figure 3. 
The major part of the local model consisted of orthotropic shell and beam elements similar to the global orthotropic shell/beam elements. A minor part of the upper orthotropic deck and diaphragm beam in the local model were modeled as a detailed shell part.

For the detailed shell part all plates (top plate, troughs, diaphragm beam with cut-outs and diaphragm beam flange) were modeled for a $5 \mathrm{~m} \times 5 \mathrm{~m}$ part of the girder. This detailed part was used to apply a finer mesh, so reliable fatigue stresses could be calculated. The detailed part was tied at all free edges as a slave connection to the master edges of the orthotropic elements, such that all displacement fields were transferred correctly.

The orthotropic shell/beam elements were meshed with a relatively coarse mesh with element size $h_{c}=1 \mathrm{~m}$ and the detailed part was in general meshed with a finer mesh of $h_{f}=0.1 \mathrm{~m}$, see Figure 3.

The terminology of an orthotropic deck (similar to the detailed shell part) used throughout the paper is given in Figure 4. The top plate and longitudinal trough, together, are named the top deck, whereas the DB web and the DB flange, together, are named the diaphragm beam.

\section{Boundary Conditions on Local Model}

The global model was established to calculate correct boundary conditions for the local model, which were applied by the "sub-model" feature in Abaqus. The principle of the "sub-model" feature is to apply displacement fields from the complete global model to the boundaries (cut edges) of the local model. Hence no fixed boundary conditions were applied to the local model.

For each load case (applied with the same configuration on both the global and the local models), the displacement fields of the global model were computed once. The displacement fields along the edges off the global orthotropic shells (indicated by dashed lines in Figure 2) were then subsequently applied to the edges of the local model (also indicated by dashed lines in Figure 2).

This method allowed for using a reduced model, and thus reduce the calculation time for the optimization process, while maintaining precise displacements along the boundaries and thus furnishing the correct stiffness of the model. 


\section{Optimization Framework}

The fundamental parts of the optimization framework illustrated in Figure 1 are specified in the following.

\section{Design Parameters}

The usual design parameters of the top deck and diaphragm beams, seen in Figure 5, were chosen as design variables. In Table 1 the initial values of the parameters (used as initial guess for the optimization) are given (equivalent to the detailed design of the Osman Gazi Bridge). Furthermore, the initial choice lower and upper bounds for all design variables are shown in the table as well.

Parametric FE Local Model To allow the design variables to change during optimization, the entire local FE model was made parametric. This way it could automatically be regenerated with the updated parameters. Various parts of the model were influenced by the updated and changing geometry, which had to be handled accordingly:

- The position of the wheel loads followed the geometry of the detailed part, hence the position, above where the fatigue stresses were calculated, was consistent as indicated in Figure 8

- The size of the detailed part varied when the geometry of the troughs changed, however, the position of the detailed part in the local model was kept consistent.

- The orthotropic shell and beam elements were assigned a customized stiffness matrix computed from the parametric design variables.

\section{Objective Functions}

Two different objective functions were implemented. The first function computes the total weight per meter of girder, hence only the material amount is minimized, and not necessarily the 
total price. The objective function in (1) computing the weight per meter is given as

$$
f_{w}(\mathbf{x})=\rho_{s}\left(A_{s p}+A_{t r}+\frac{V_{D}}{L_{d}}\right)
$$

where $\rho_{s}$ is density of steel, $A_{s p}$ is the cross section area of all outer skin plates, $A_{t r}$ is the cross section area of all troughs, and $V_{D}$ is the total volume of a single diaphragm. The weight function is implicitly a function of the design variables $\mathbf{x}$.

To handle a minimization of the total price of the bridge girder, a second objective function was implemented, including a differentiation on the steel price, besides welding and manufacturing costs. The steel and welding prices were estimated by experienced bridge design engineers. However, exact prices were not crucial in the scope of optimization, but only the ratio between the different prices. This objective function is given as

$$
f_{p}(\mathbf{x})=P_{1}(\mathbf{x})+P_{2}(\mathbf{x})
$$

where $P_{1}(\mathbf{x})$ is the price per meter of the top plate, troughs under the top plate and the diaphragm beams, and $P_{2}(\mathbf{x})=20,163 \mathrm{EUR} / \mathrm{m}$ is a fixed price of the rest of the girder per meter (with an estimated steel price of $2.7 \mathrm{EUR} / \mathrm{kg}$ incl. manufacturing costs). Price function $P_{1}(\mathbf{x})$ is given implicitly as a function of the design variables $\mathbf{x}$ as

$$
\begin{aligned}
P_{1}(\mathbf{x})= & \rho_{s}\left[A_{t p} P_{t p}+A_{t r} P_{t r}+\frac{V_{D B}}{L_{d}} P_{D B}+P_{w, a}\left(A_{w, t r-t p}+A_{w, t p}+\frac{V_{w, D B_{f l}-D B_{w}}}{L_{d}}\right)\right. \\
& \left.+P_{w, m}\left(\frac{V_{w, t p-D B_{w}}}{L_{d}}+\frac{V_{w, t r-D B_{w}}}{L_{d}}\right)\right]
\end{aligned}
$$

where

- $A_{t p}$ is the cross section area of the top plate

- $P_{t p}=1.3 \mathrm{EUR} / \mathrm{kg}$ is an estimated steel price on the top plate

- $P_{t r}=1.6 \mathrm{EUR} / \mathrm{kg}$ is an estimated steel price on the troughs (incl. machining costs)

- $V_{D B}$ is the volume of a single diaphragm beam 
- $P_{D B}=1.5 \mathrm{EUR} / \mathrm{kg}$ is an estimated steel price on diaphragm beams (incl. machining costs)

- $P_{w, a}=95.2 \mathrm{EUR} / \mathrm{kg}$ is an estimated price on automated welding

- $A_{w, t r-t p}$ is the total cross section area of the longitudinal weldings between troughs and top plate

- $A_{w, t p}$ is the total cross section area of the longitudinal weldings in the top plates

- $V_{w, D B_{f l}-D B_{w}}$ is the total volume of the weldings between the diaphragm beam flange and web for a single diaphragm beam

- $P_{w, m}=333$ EUR/kg is an estimated price on manual welding (incl. fitting)

- $V_{w, t p-D B_{w}}$ is the total volume of the weldings between top plate and diaphragm beam for a single diaphragm beam

- $V_{w, t r-D B_{w}}$ is the total volume of the weldings between troughs and diaphragm beam for a single diaphragm beam

Potentially, the two different optimization goals can yield different results of the design variables, and usually, the price function is most desirable for the design engineer. However, a minimization of total price of the bridge girder is not necessarily the best optimization goal in regard of total construction cost of the entire cable supported bridge; as a minimized girder weight will have knock-on effects on cables, towers and sub-structure. Hence, a reduced girder weight will lead to reduced hanger and main cable areas, reduced cables forces, and thus reduced anchor blocks. These knock-on effect may lead to a lower total construction cost. However, such a study is outside the scope of this paper, where only the weight and price of the bridge girder itself is in focus. The main focus has thus been on weight minimization, as the weight is a clear and unambiguous measure, and due to the general goal of reducing the girder weight.

\section{Constraint Functions}

Several different constraint functions were implemented to ensure that the optimized designs are not subject to fatigue or buckling issues, and fulfill stiffness and deformation requirements. The different types of constraint functions are elaborated below, where several were computed from the 
local finite element model.

Fatigue Mitigation of fatigue issues is one of the main design drivers for orthotropic steel bridge girders. The computation and analysis of fatigue stresses in a general design process of a bridge girder is a comprehensive and very detail oriented task. Therefore, several simplifications have been introduced to include fatigue as constraint functions in the optimization process, as described below.

The number of fatigue details have been reduced to three of the most important for the specific bridge, see Figure 6, which were identified in (Bjærre 2015) and from the experience gained by COWI A/S through actual design work. The limited choice of fatigue details has been reasoned to ensure acceptable computation times during the optimization. In Table 2 information about the details are given.

In (Bjærre 2015) it was also shown that for these three details the major contribution to fatigue damage came from the vehicle type 5A-H truck in the Eurocode 1993-1-9 UK annex fatigue load model 4 (FLM4) (which the fatigue design of the Osman Gazi Bridge was based upon). Thus, this truck load was the only load configuration considered for the fatigue details. The configuration of 5A-H with axle loads is seen in Figure 7.

For the three fatigue details in Table 2 the largest stress variations occur for different axle positions, see column 2 in Table 3. For FD1 and FD4 a single truck position (load case LC1 and LC7, respectively) were included, whereas for FD3 two truck positions (load case LC5 and LC6) were included. The position of the axles for the four load cases on the detailed shell part is shown in Figure 8. In the figure a reference point is indicated, and the detailed shell part and the axle positions were defined relative to this point, during optimization. The fatigue stresses were measured near the reference point during the optimization.

Finally, the usual Palmgren-Miner summation was reduced to critical target stresses for each fatigue detail. Hence, the constraint functions for the three fatigue details were established in such a way that calculated fatigue stresses in the details were acceptable if below the target. The target 
stresses are shown in Table 3 and have been identified by COWI A/S during the design work.

Around the fatigue details the mesh was discretized according to XIII-1823-07 IIW Recommendations for fatigue design of welded joints and components 2008 (sect. 2.2.3.4 - type "a" hot spots). The fatigue stresses at the weldings were calculated by the hot spot method given as

$$
\sigma_{h s}=1.50 \sigma_{0.5 t}-0.50 \sigma_{1.5 t}
$$

where $\sigma_{0.5 t}$ and $\sigma_{1.5 t}$ are the stresses calculated respectively at $0.5 t$ and $1.5 t$ from the connection, and $t$ being the plate thickness. Consequently, the mesh around the fatigue details was discretized to the fineness seen in Figures 9, 10 and 11 for fatigue details FD1, FD3, and FD4, respectively. In the figures the relevant stress fields are shown.

The fatigue performance and resistance of the details are dependent on the changing design parameters, which should be considered when studying the results. However, the magnitude of change in design variables has been considered to be acceptable in relation to the use a constant target stress.

EN stiffness requirement The minimum stiffness requirement to longitudinal stiffeners (troughs) in Eurocode EN 1993-2-2007 Annex C.1.2.2 - Fig. C.4 was introduced as a constraint function in the optimization. The requirement describes the upper limit on the ratio between the diaphragm distance $L_{d}$ and the moment of inertia $I_{B}$ of the troughs including top plate. The constraint function, based on the empirical graph in Eurocode, is given as

$$
c_{\text {stiff. }}=\frac{L_{d}-2.8939}{9000 I_{B}}-1 \leq 0
$$

where $L_{d}$ and $I_{B}$ both are given in SI-units. The constraint is designated EN stiff. req. in the following. 
Deflection criterion Besides the stiffness requirement from the Eurocode a simple deflection criterion was included. A maximum acceptable relative vertical deflection between two adjacent diaphragms was given as 1/400. Hence, the deflection criterion is shown in Figure 12, and the constraint function is given as

$$
c_{\text {def. }}=\frac{d}{L_{d}} \leq 1 / 400 \Leftrightarrow c_{\text {def. }}=\frac{d}{L_{d}}-1 / 400 \leq 0
$$

The load case giving the maximum deflection is the case where three rear axles of truck 5A-H are positioned in between two diaphragms.

This constraint is designated Defl. crit. in the following.

Buckling Buckling is often a concern in thin plated structures such as orthotropic steel girders. Hence, a constraint against buckling was made for the four load cases from the fatigue details and the fifth load case from the deflection criterion. Initial studies carried out before the optimization, however, showed that buckling would not be an issue for these load cases. Thus the buckling constraint was not included during the optimization, but carried out as a check of the final design after optimization to ensure that stability was not an issue.

\section{RESULTS}

The developed optimization framework was applied for nine cases, as outlined in Table 4 (column 1-5). In Case 1-8 the objective is minimization of weight and in Case 9 the objective is minimization of price. The initial weight and price of the girder, with dimensions given in Table 1 , are $12.81 \mathrm{ton} / \mathrm{m}$ and $34,170 \mathrm{EUR} / \mathrm{m}$, respectively. In the first three cases the complexity of the optimization is increased from one design variable to five and ten design variables, respectively, after which ten design variables are used in the remaining cases. The lower bound on the plate thicknesses varies for some of the different cases, where the point of reference is $5 \mathrm{~mm}$, as indicated in Table 1.

For all optimization cases the four fatigue load cases and the deflection criterion are included. The inclusion of the EN stiffness requirement varies though from case to case, as it appears to 
be very constraining on the optimization, and thus interesting to leave out in some cases. The constraint function limits, initial values, and values after optimization for all cases are summarized in Table 5. From the table it is seen that all constraints are fulfilled (below the maximum limit) for all cases. It is further noticed that FD1, FD4, and EN stiff. req. are the constraints limiting the optimization, whereas the defl. crit. in all cases is far from its limit. The EN stiff. req. is thus clearly the most strict of the two deformation criteria. The data in Table 5 is further elaborated upon in the following subsections.

From Table 5 it is noticed how the fatigue constraints newer reach their maximum limits exactly (as the EN stiff. req. does), but only come very close. The reason for this lies in the coupling between the Abaqus FE model and the optimization in Matlab, and in the use of finite difference gradients. The non-smooth steps taken by the optimization algorithm to generate the gradients, results in non-smooth responses from the FE model. The non-smooth responses from the FE model is mainly due to re-meshing. It is thus expected that the fatigue constraints cannot reach their limits exactly.

For all optimization cases the start guess was the original design, however, optimization with random start guesses have been carried out to ensure that the same final values were obtained. Even though this is the case for all presented results, it is no guaranty for global minimum. Furthermore, a buckling check has been carried out for all final results, to ensure that there are no stability issues.

The main results for all cases are summarized in Table 4 (column 6-7), where both the savings in weight and price are shown relative to the initial design. These results are elaborated upon in the following subsections, where the results for all cases are presented and discussed.

\section{Minimization of girder weight}

The first eight cases have the objective function: minimization of the girder weight per meter. This is the most simple of the two objective functions. In Case 1 to 3 the complexity increases with the number of free design variables. In Case 3 to 8 two effects are studied: (a) the influence of different lower bounds on plate thicknesses and (b) the effect of the EN stiffness requirement. 


\section{Case 1 - One design variable}

In Case 1 the diaphragm distance $L_{d}$ is the only free design variable. The objective function, constraint functions and design variable as a function of iteration number are seen in Figure 13. In the figure, the constraint functions are all normalized with their initial values (row 2 in Table 5) and defined on the form in (1), hence function values below 0 are acceptable.

The initial diaphragm distance was $L_{d}=5 \mathrm{~m}$ and the optimized distance was found to $L_{d}=5.43$ $\mathrm{m}$, which gives a saving of $0.4 \%$ in weight $(0.05 \mathrm{ton} / \mathrm{m})$. This distance is thus optimal, when all other parameters are fixed to their initial values. The reason for the relatively low weight reduction is found in the general relatively low contribution from the diaphragms to the total amount of steel in the girder.

When studying the constraint functions (row 3 in Table 5) it is found that the maximum limit on the Eurocode stiffness requirement is reached, and hence acts as the stopping criterion for the optimization algorithm. Furthermore, it is noticed how all fatigue stresses have increased slightly, but in general they are not effected by the changing diaphragm distance.

\section{Case 2 - Five design variables}

The complexity of the optimization problem is increased slightly in Case 2, where the free design variables are the diaphragm distance $L_{d}$ and the four plate thicknesses $t_{t p}, t_{t r}, t_{w}$, and $t_{f}$. The objective function, constraint functions and design variables as a function of iteration number are seen in Figure 14. In the figure, the design variables are all normalized with respect to their initial values (column 3 in Table 1), and the constraint functions are normalized as well.

The weight saving is found to $5.7 \%$, equivalent to $0.72 \mathrm{ton} / \mathrm{m}$ and in total 1,931 ton for the 2,682 $\mathrm{m}$ long bridge girder. The knock-on effects on cables, towers and sub-structure, as discussed previously, are also assumed to be significant. These knock-on effects are inherently present for all the optimization cases.

The initial and final values of the five design variables are seen in Table 6.

From Table 6 it is seen that the diaphragm distance $L_{d}$ and diaphragm web thickness $t_{w}$ are only changed slightly and the top plate thickness $t_{t p}$ is unchanged, whereas the trough thickness $t_{t r}$ and 
flange thickness $t_{f}$ are reduced considerably ( $t_{f}$ reaching its lower boundary). Hence, it is these two last design variables, and especially the trough thickness, which contribute to weight savings. Even though the plate thicknesses are reduced significantly no buckling issues have been detected for the given load cases.

When comparing the final value of the diaphragm distance with the Case 1 result, it is seen that the change from the initial value is now in the opposite direction. Hence, when adding more design variables it is more beneficial for the optimization algorithm to reduce the diaphragm distance to allow for a reduction in plate thicknesses. The reduction of the plate thicknesses is clearly more beneficial for the objective function than the increase in diaphragm distance. This finding indicates the benefits of using optimization tools in the design process, when the number of unknowns increase.

When looking at the constraint functions (row 4 in Table 5) it is seen again that the maximum limit on the Eurocode stiffness requirement is the stopping criterion for the optimization. However, it is also noticed that the fatigue stress limits for fatigue details FD1 and FD4 are almost reached, and thus are close to being active stopping constraints. Interestingly, it is seen that the fatigue stresses for fatigue detail FD3 (for both load cases) have decreased from their initial values.

\section{Case 3 to 8 - Ten design variables}

The complexity of the problem is finally increased fully as all ten design variables are free in the optimization problem in Case 3 to 8 . The initial and final design variables for Case 3 to 8 are summarized in Table 7.

From the table, in general the major changes are seen in reduced trough thickness $t_{t r}$ and flange thickness $t_{f}$, minor changes are seen in $h_{t r}, w_{t r, b}, t_{w}$, and $w_{f}$, whereas design parameters $L_{d}, t_{t p}$, $w_{t r, t}$, and $h_{w}$ in general only experience slight changes. The largest contribution to weight savings comes from reduced trough thickness, as the troughs account for a much larger part of the deck than the diaphragm beam flanges. The reduction of trough thickness is seen to influence the other design variables during the optimization, and hence is governing the design.

In the following, Case 3 is presented similarly to Case 1 and 2, followed by the studies including 
Case 3 to 8 .

Case 3 The objective function, constraint functions and design variables as a function of iteration number are seen in Figure 15. In the figure, constraint functions and design variables are normalized.

The weight saving is found to $7.9 \%$, equivalent to 1.0 ton/m, or in total 2,682 ton for the entire girder.

For the five design variables from Case 2, slight changes are seen in Case 3 as a result of the higher degree of freedom due to the increase in the number of free design variables. The top plate thickness $t_{t p}$ is reduced slightly, and the diaphragm distance $L_{d}$ is increased. Furthermore, both the trough and flange thicknesses $\left(t_{t r}\right.$ and $\left.t_{f}\right)$ are reduced to the lower bound of $5 \mathrm{~mm}$. Finally, it is seen that both the top width $w_{t r, t}$ and bottom width $w_{t r, b}$ of the troughs are reduced (hence the number of troughs is increased), whereas the trough height $h_{t r}$ is increased to compensate for the loss of moment of inertia. Hence, the trend is more but narrower troughs in the orthotropic deck plate, when weight reduction is the goal. This trend together with the reduced plate thicknesses are the reasons for the relatively large weight savings.

When studying the constraint functions (row 5 in Table 5), it is seen that no constraint limits are reached, although the EN stiff. req. is very close (similar to Case 1 and 2). Instead the limiting factors are the lower bounds on the trough and flange thicknesses.

Variation in lower bounds and relaxation of EN stiff. req. From the results of Case 1 to 3 it was clear that the most limiting constraint function was the EN stiff. req., and from Case 3 it was seen how the lower bound on plate thicknesses was the limiting factor. In the following the effect of these two aspects are considered in more detail.

In Case 5 and 7 the lower bound on the plate thicknesses is increased to $6 \mathrm{~mm}$ and reduced to $4 \mathrm{~mm}$, respectively. Case 5 with minimum $6 \mathrm{~mm}$ trough thickness is thus fully aligned with the requirements in the Eurocode EN 1993-2-2007. In contrast Case 7 allows the optimization to further utilize even smaller plate thicknesses.

Case 4, 6, and 8 are all similar to Case 3, 5, and 7, respectively, but without the EN stiff. 
req. constraint. The EN stiff. req. is included in the Eurocode to ensure enough stiffness in the orthotropic deck to prevent cracks in the surface and to ensure a limit on the vertical deflections. However, it is seen to be more strict than the simple deflection criterion. Thus, the three cases show how the design would evolve if the EN stiff. req. is either disregarded or just relaxed.

The main results for Case 3 to 8 are summarized in Figure 16, where Case 3, 5, and 7 (with EN stiff. req.) and Case 4, 6, and 8 (without EN stiff. req.) are grouped, respectively. In addition to Figure 16 the relative weight savings are seen in Table 4.

From Figure 16 it is seen that by removing the EN stiff. req. the weight savings are in general higher, and with an increasing effect when the lower bound is reduced as well. The increased difference between Case 7 and 8, is due to the EN stiff. req. constraint being active in Case 7, contrary to Case 3 and 5. Furthermore, it is seen that the gain in reducing the lower bound from $5 \mathrm{~mm}$ to $4 \mathrm{~mm}$ is higher when the EN stiff. req. is disregarded.

When considering the results shown in Table 4 and 7 several additional conclusions can be deducted, as follows.

Case 5 shows, that the maximum weight savings with all Eurocode requirements fulfilled is $5.8 \%$ (equivalent to a price saving of $8.7 \%$ ). In this case it is mainly the trough and flange thicknesses which are reduced, whereas most other parameters only experience minor changes. In Case 7 the lower bound on plate thicknesses are not reached for any of the plates, hence the maximum weight saving including the EN stiff. req. is $8.4 \%$ (equivalent to a price saving of $11.2 \%$ ). By disregarding the requirement of minimum $6 \mathrm{~mm}$ trough thickness, an additional weight saving of 2.6 percentage points is thus achievable. It is further noticed that Case 7 is the only case (of all nine) where no variables reach lower nor upper bounds.

In Case 4, 6, and 8 the effect of disregarding the EN stiff. req. constraint is clearly seen in the change of trough height $h_{t r}$ compared to Case 3, 5, and 7, respectively. The trough height is reduced significantly in all three cases, as no compensation in total trough stiffness is required. This reduction is governing for the additional weight savings in Case 4 and 6, and partly in Case 8 . With the final design in the three cases the EN stiff. req. is exceeded by $13.7 \%$ in Case $6,25.8 \%$ 
in Case 4 and 205.3\% in Case 8. The limit of the deflection criterion for the three cases is far from being reached (see column 6 in Table 5), even though the deck stiffness is reduced considerably due to the weight savings. This further indicates that the Eurocode stiffness requirement is very strict.

Finally, some additional comments about Case 8 are emphasized. As Case 8 both has very low bounds on plate thickness and no EN stiff. req. constraint, the case is considered to be an academic example to indicate potential savings if the Eurocode requirements were reassessed. The potential weight and price savings, of respectively $13.8 \%$ and $16.7 \%$, are significantly higher than for any other case. When studying the change in design parameters, Case 8 is also noticeable. The diaphragm distance is increased to $L_{d}=5.76 \mathrm{~m}$ and top plate thickness is reduced to $t_{t p}=12.3$ $\mathrm{mm}$, together with the significant reduction in all trough dimensions. The trend towards more but narrower and thinner troughs is thus similar to several of the other cases in Table 7.

\section{Minimization of girder price}

The final Case 9 is similar to Case 3, but with the objective of minimizing girder price per meter. The price function includes, besides a differentiation on the price on steel, also welding and manufacturing costs. The price reduction obtained is $11.9 \%$ compared to $11.8 \%$ for Case 3 , and the final design variables are seen in Table 8.

From Table 8 it is seen how the changes in design variables are very similar to the changes seen in Case 3. As both the price savings and variable changes are very similar it can be concluded that changing the objective from minimizing weight to minimizing price does not influence the results significantly. The additional effects of welding and other manufacturing costs are thus not large enough compared to the effect of the price on steel (basically a scaling of the weight) to have an impact on the results.

\section{CONCLUSIONS}

A multi-scale FE model with sophisticated boundary conditions of a single section of an orthotropic bridge girder was established to form the basis of an automated gradient-based parametric optimization. The optimization framework facilitated simultaneous optimization of up to ten design parameters with the goal of minimizing either weight or price of the girder. Concurrently 
with the optimization, constraint functions including fatigue stresses, EN stiffness requirements and deflection criterion were fulfilled, hence ensuring acceptable final designs.

From the nine optimization cases potential weight savings were found in the range of $5.8 \%$ $13.8 \%$ and price savings in the range of $8.7-16.7 \%$. The maximum weight saving with all current Eurocode requirements fulfilled was found to $5.8 \%$ (8.7\% price reduction), equivalent to 1,990 ton of steel for the entire girder. It should be mentioned, that the initial design already before optimization was considered to be state-of-the-art.

The complexity of the optimization cases was step-wise increased from a single design variable to five and ultimately ten free variables. When increasing the complexity of the problem it became apparent how the optimization algorithm was capable of utilizing the additional design variables towards a better design in regard of the objective function. These results indicated the benefits of using optimization tools in the design process, when the number of unknown increase, and thus the complexity of the problem.

From the initial optimization cases it was apparent that two limiting factors were governing in the optimizations: the Eurocode stiffness requirement and the lower bound on plate thicknesses. By disregarding the EN stiff. req. potential weight savings of $6.7 \%$ were achievable and by lowering the bound on plate thickness from $6 \mathrm{~mm}$ to $4 \mathrm{~mm}$ potential weight savings of $8.4 \%$ were found. A combination of the two above relaxations showed theoretical weight savings of up to $13.8 \%(16.7 \%$ price reduction) without any other constraints being exceeded. The results thus indicate potential additional weight and price savings if the Eurocode requirements were reassessed.

In general the trends in the designs were towards more, but narrower and thinner troughs, however, with an increased trough height to compensate the lost total trough stiffness. Furthermore, the reduction of trough thickness seemed to influence the other design variables during optimization, and hence govern the design. With the change in objective function from weight to price, similar trends were seen, concluding with no significant differences in output between the two objective functions.

Furthermore, the study demonstrated how gradient-based optimization tools in principle can 
be utilized in design tasks of civil engineering structures to identify both trends and actual weight or price savings. Compared to previous parameter studies of single variables, the high complexity of multiple parameters is easily managed by the gradient-based optimization algorithm, and thus enables the full utilization of orthotropic bridge girders.

\section{DATA AVAILABILITY STATEMENT}

Some or all data, models, or code generated or used during the study are available from the corresponding author by request. This includes the multi-scale Abaqus FE-model and the Matlab optimization framework.

\section{ACKNOWLEDGEMENTS}

The presented work is part of an industrial $\mathrm{PhD}$ project with the title "Innovative design of steel bridge girders in cable supported bridges" and is carried out in cooperation with COWI A/S, DTU Civil Engineering and DTU Mechanical Engineering. The project is supported financially by the COWI Foundation grant C-131.02 and Innovation Fund Denmark grant 5189-00112B.

\section{REFERENCES}

Abaqus (2016). “Documentation.” Dassault Systemes.

Andersen, S. and Hansen, U. M. (2012). "Static and dynamic analysis of Izmit Bay Bridge.” M.Sc. thesis, Technical University of Denmark, Kgs. Lyngby, Denmark.

Bjærre, S. (2015). "Improvements to present design philosophy of orthotropic steel decks with focus on fatigue.” M.Sc. thesis, Technical University of Denmark, Kgs. Lyngby, Denmark.

Byrd, R. H., Nocedal, J., and Waltz, R. A. (2006). "Knitro: An integrated package for nonlinear optimization." Large-Scale Nonlinear Optimization. Nonconvex Optimization and Its Applications, $83,35-59$.

Connor, R. (2004). "Influence of cutout geometry on stresses at welded rib-to-diaphragm connections in steel orthotropic bridge decks." Transportation Research Record: Journal of the Transportation Research Board, 1892, 78-87. 
De Backer, H., Outtier, A., and Van Bogaert, P. (2006). "Analytical model for the stiffener-todeck plate detail in orthotropic bridges." Proceedings of the 10th East Asia-Pacific Conference on Structural Engineering and Construction, Vol. 2, Analytical and Computational Methods, 47-52.

De Corte, W. (2009). "Parametric study of floorbeam cutouts for orthotropic bridge decks to determine shape factors." Bridge Structures, 5(2-3), 75-85.

De Corte, W. and Van Bogaert, P. (2007). "Improvements to the analysis of floorbeams with additional web cutouts for orthotopic plated decks with closed continuous ribs." Steel and Composite Structures, 7(1), 1-18.

Ding, B. D., Lv, H. L., and Ji, Y. S. (2010). "Finite Element Model Updating Based on Direct Optimization Technique.” Advanced Materials Research, 163-167(4), 2804-2810.

Fettahoglu, A. (2015). "Effect of cross-beam on stresses revealed in orthotopic steel bridges." Steel and Composite Structures, 18(1), 149-163.

Fettahoglu, A. (2016). "Optimizing rib width to height and rib spacing to deck plate thickness ratios in orthotropic decks." Cogent Engineering, 3(1).

Fisher, J. W. and Dexter, R. J. (1997). "Fatigue cracking of orthotropic steel decks." IABSE reports, 76.

MATLAB (2016). “R2016b documentation.” The MathWorks Inc.

Mrsa, Z. and Medic, G. (1996). “Optimal nozzle design using finite element conjugate gradient based software." Hydraulic Engineering Software Vi, Computational Mechanics Publications, 479-488.

Nagar, S. (2018). "Introduction to Python Basics." Introduction to Python for Engineers and Scientists, Apress, Berkeley, CA, 13-30.

Oh, C. K. and Bae, D. (2013). "Fatigue test of an advanced orthotropic steel deck system using high performance steel for bridges." International Journal of Steel Structures, 13(1), 93-101.

Oh, C. K., Hong, K. J., Bae, D., Do, H., and Han, T. (2011). “Analytical and experimental studies on optimal details of orthotropic steel decks for long span bridges." International Journal of 
Steel Structures, 11(2), 227-234.

Peng, H., Jun, M., and Bing, X. (2005). “FEM-based parametric optimization design of wedge-ring joint structure.” Journal of Mechanical Strength, 27(2), 191-195.

Tang, M.-C. (2011). “A new concept of orthotropic steel bridge deck.” Structure and Infrastructure Engineering, 7(7-8), 587-595.

Wolchuk, R. (1990). "Lessons from weld cracks in orthotropic decks on 3 european bridges." Journal of Structural Engineering, 116(1), 75-84.

Wolchuk, R. (1999). “Steel orthotropic decks: developments in the 1990s.” Transportation Research Record 1688, (99-0430), 30-37.

Wolchuk, R. and Harris, F. R. (1959). “Orthotropic plate design of steel bridges.” Civil Engineering, $38-43$. 


\section{List of Tables}

1 Design parameters and initial values . . . . . . . . . . . . 25

2 Information on fatigue details . . . . . . . . . . . . . . 26

3 Truck position and simplified fatigue stresses . . . . . . . . . . . . 27

4 Definition of studied optimization cases, including weight and price reductions after optimization (objective function in bold) . . . . . . . . . . . 28

5 Constraint function limits, initial values, and values after optimization for all cases 29

6 Initial and final design variables for Case 2 with five design variables . . . . . . . 30

7 Initial and final design variables for Case 3 to 8 with ten design variables . . . . . 31

8 Initial and final design variables for Case 9 with ten design variables . . . . . . . 32 
TABLE 1. Design parameters and initial values

\begin{tabular}{lcrrr}
\hline \hline Design parameter & Symbol & $\begin{array}{r}\text { Initial value } \\
{[\mathrm{mm}]}\end{array}$ & $\begin{array}{r}\text { Lower bound } \\
{[\mathrm{mm}]}\end{array}$ & $\begin{array}{r}\text { Upper bound } \\
{[\mathrm{mm}]}\end{array}$ \\
\hline Diaphragm distance & $L_{d}$ & 5,000 & 4,170 & 6,250 \\
Top plate thk. & $t_{t p}$ & 14 & 5 & 20 \\
Trough thk. & $t_{t r}$ & 8 & 5 & 15 \\
Trough height & $h_{t r}$ & 360 & 100 & 600 \\
Trough width top & $w_{t r, t}$ & 300 & 200 & 400 \\
Trough width bottom & $w_{t r, b}$ & 180 & 50 & 300 \\
DB web height & $h_{w}$ & 1,000 & 500 & 1,500 \\
DB web thk. & $t_{w}$ & 14 & 5 & 20 \\
DB flange width & $w_{f}$ & 250 & 50 & 500 \\
DB flange thk. & $t_{f}$ & 12 & 5 & 20 \\
\hline \hline
\end{tabular}


TABLE 2. Information on fatigue details

\begin{tabular}{|c|c|c|c|c|}
\hline ID & Location & Detail category & Detail in EN 1993-1-9 & Stress direction \\
\hline FD1 & Diaphragm cut-out & 125 & Table 8.1 detail 5 & $\begin{array}{l}\text { Max. principal stress along } \\
\text { cut-out }\end{array}$ \\
\hline FD3 & $\begin{array}{l}\text { Trough to top plate } \\
\text { welding }\end{array}$ & 71 & Table 8.8 detail 7 & $\begin{array}{l}\text { Transverse direct stress in } \\
\text { underside of the top plate }\end{array}$ \\
\hline FD4 & $\begin{array}{l}\text { Top plate to di- } \\
\text { aphragm welding }\end{array}$ & 71 & Table 8.4 detail 8 & $\begin{array}{l}\text { Longitudinal direct stress } \\
\text { in underside of the top plate }\end{array}$ \\
\hline
\end{tabular}


TABLE 3. Truck position and simplified fatigue stresses

\begin{tabular}{|c|c|c|}
\hline ID & Contributing 5A-H vehicle axles & Target stress \\
\hline FD1 & $\begin{array}{l}\text { Three rear axles above di- } \\
\text { aphragm (LC1) }\end{array}$ & $65 \mathrm{MPa}$ \\
\hline FD3 & $\begin{array}{l}\text { First (LC5) and second (LC6) } \\
\text { axle, individually, approx. } 0.6 \\
\text { m from diaphragm }\end{array}$ & $40 \mathrm{MPa}$ \\
\hline FD4 & $\begin{array}{l}\text { First axle right next to di- } \\
\text { aphragm (LC7) }\end{array}$ & $38 \mathrm{MPa}$ \\
\hline
\end{tabular}


TABLE 4. Definition of studied optimization cases, including weight and price reductions after optimization (objective function in bold)

\begin{tabular}{|c|c|c|c|c|c|c|}
\hline Case & Objective & $\begin{array}{c}\text { No. of design } \\
\text { variables }\end{array}$ & $\begin{array}{l}\text { Lower bound } \\
\text { on plate thk. }\end{array}$ & EN stiff. req. & $\begin{array}{c}\text { Weight } \\
\text { saved }\end{array}$ & $\begin{array}{l}\text { Price } \\
\text { saved }\end{array}$ \\
\hline 1 & \multirow{8}{*}{ Weight } & 1 & \multirow{4}{*}{$5 \mathrm{~mm}$} & \multirow{3}{*}{ Yes } & $0.4 \%$ & $0.3 \%$ \\
\hline 2 & & 5 & & & $5.7 \%$ & $8.6 \%$ \\
\hline 3 & & \multirow{7}{*}{10} & & & $7.9 \%$ & $11.8 \%$ \\
\hline 4 & & & & No & $8.9 \%$ & $12.5 \%$ \\
\hline 5 & & & \multirow{2}{*}{$6 \mathrm{~mm}$} & Yes & $5.8 \%$ & $8.7 \%$ \\
\hline 6 & & & & No & $6.7 \%$ & $9.2 \%$ \\
\hline 7 & & & \multirow{2}{*}{$4 \mathrm{~mm}$} & Yes & $8.4 \%$ & $11.2 \%$ \\
\hline 8 & & & & No & $13.8 \%$ & $16.7 \%$ \\
\hline 9 & Price & & $5 \mathrm{~mm}$ & Yes & $7.6 \%$ & $11.9 \%$ \\
\hline
\end{tabular}


TABLE 5. Constraint function limits, initial values, and values after optimization for all cases

\begin{tabular}{lcccccc}
\hline \hline Case & $\begin{array}{c}\text { FD1 - LC1 } \\
{[\mathrm{MPa}]}\end{array}$ & $\begin{array}{c}\text { FD3 - LC5 } \\
{[\mathrm{MPa}]}\end{array}$ & $\begin{array}{c}\text { FD3 - LC6 } \\
{[\mathrm{MPa}]}\end{array}$ & $\begin{array}{c}\text { FD4 - LC7 } \\
{[\mathrm{MPa}]}\end{array}$ & $\begin{array}{c}\text { Defl. crit. } \\
{[-]}\end{array}$ & $\begin{array}{c}\text { EN stiff. req. } \\
{[-]}\end{array}$ \\
\hline Max. limit: & 65.00 & 40.00 & 40.00 & 38.00 & $1 / 400$ & 0.000 \\
Initial value: & 57.87 & 32.80 & 36.59 & 37.67 & $1 / 5,058$ & -0.170 \\
Case 1: & 59.87 & 33.14 & 36.73 & 37.73 & $1 / 4,494$ & 0.000 \\
Case 2: & 64.99 & 30.93 & 35.59 & 37.91 & $1 / 4,314$ & 0.000 \\
Case 3: & 64.56 & 29.90 & 35.10 & 37.49 & $1 / 4,065$ & -0.002 \\
Case 4: & 64.16 & 29.96 & 35.16 & 37.91 & $1 / 3,493$ & NA \\
Case 5: & 64.94 & 30.96 & 36.03 & 37.90 & $1 / 4,172$ & -0.014 \\
Case 6: & 64.98 & 31.42 & 36.29 & 37.79 & $1 / 3,894$ & NA \\
Case 7: & 63.70 & 27.38 & 32.61 & 37.97 & $1 / 4,125$ & 0.000 \\
Case 8: & 63.83 & 27.94 & 34.17 & 37.98 & $1 / 1,966$ & NA \\
Case 9: & 64.73 & 29.17 & 34.54 & 37.84 & $1 / 4,075$ & 0.000 \\
\hline \hline
\end{tabular}


TABLE 6. Initial and final design variables for Case 2 with five design variables

\begin{tabular}{rccccc}
\hline \hline Case & $\begin{array}{c}L_{d} \\
{[\mathrm{~m}]}\end{array}$ & $\begin{array}{c}t_{t p} \\
{[\mathrm{~mm}]}\end{array}$ & $\begin{array}{c}t_{t r} \\
{[\mathrm{~mm}]}\end{array}$ & $\begin{array}{c}t_{w} \\
{[\mathrm{~mm}]}\end{array}$ & $\begin{array}{c}t_{f} \\
{[\mathrm{~mm}]}\end{array}$ \\
\hline Initial: & 5 & 14 & 8 & 14 & 12 \\
Case 2: & 4.96 & 14.0 & 6.0 & 13.2 & 5.0 \\
\hline \hline
\end{tabular}


TABLE 7. Initial and final design variables for Case 3 to 8 with ten design variables

\begin{tabular}{rcccccccccc}
\hline \hline Case & $\begin{array}{c}L_{d} \\
{[\mathrm{~m}]}\end{array}$ & $\begin{array}{c}t_{t p} \\
{[\mathrm{~mm}]}\end{array}$ & $\begin{array}{c}t_{t r} \\
{[\mathrm{~mm}]}\end{array}$ & $\begin{array}{c}h_{t r} \\
{[\mathrm{~mm}]}\end{array}$ & $\begin{array}{c}w_{t r, t} \\
{[\mathrm{~mm}]}\end{array}$ & $\begin{array}{c}w_{t r, b} \\
{[\mathrm{~mm}]}\end{array}$ & $\begin{array}{c}h_{w} \\
{[\mathrm{~mm}]}\end{array}$ & $\begin{array}{c}t_{w} \\
{[\mathrm{~mm}]}\end{array}$ & $\begin{array}{c}w_{f} \\
{[\mathrm{~mm}]}\end{array}$ & $\begin{array}{c}t_{f} \\
{[\mathrm{~mm}]}\end{array}$ \\
\hline Initial: & 5.00 & 14.0 & 8.0 & 360.0 & 300.0 & 180.0 & 1000.0 & 14.0 & 250.0 & 12.0 \\
Case 3: & 5.02 & 13.9 & 5.0 & 390.9 & 296.1 & 166.2 & 1007.2 & 12.7 & 238.7 & 5.0 \\
Case 4: & 5.01 & 13.8 & 5.0 & 354.6 & 294.2 & 167.4 & 1004.5 & 12.9 & 244.7 & 5.0 \\
Case 5: & 5.00 & 13.9 & 6.0 & 367.4 & 300.0 & 174.4 & 1000.4 & 12.9 & 182.8 & 6.0 \\
Case 6: & 5.00 & 13.6 & 6.0 & 349.2 & 292.9 & 169.7 & 979.4 & 12.7 & 243.9 & 8.6 \\
Case 7: & 4.99 & 14.4 & 4.2 & 396.0 & 300.3 & 203.5 & 998.0 & 13.9 & 242.3 & 4.1 \\
Case 8: & 5.76 & 12.3 & 4.0 & 311.2 & 250.3 & 153.8 & 986.5 & 14.6 & 77.9 & 4.0 \\
\hline \hline
\end{tabular}


TABLE 8. Initial and final design variables for Case 9 with ten design variables

\begin{tabular}{rcccccccccc}
\hline \hline Case & $\begin{array}{c}L_{d} \\
{[\mathrm{~m}]}\end{array}$ & $\begin{array}{c}t_{t p} \\
{[\mathrm{~mm}]}\end{array}$ & $\begin{array}{c}t_{t r} \\
{[\mathrm{~mm}]}\end{array}$ & $\begin{array}{c}h_{t r} \\
{[\mathrm{~mm}]}\end{array}$ & $\begin{array}{c}w_{t r, t} \\
{[\mathrm{~mm}]}\end{array}$ & $\begin{array}{c}w_{t r, b} \\
{[\mathrm{~mm}]}\end{array}$ & $\begin{array}{c}h_{w} \\
{[\mathrm{~mm}]}\end{array}$ & $\begin{array}{c}t_{w} \\
{[\mathrm{~mm}]}\end{array}$ & $\begin{array}{c}w_{f} \\
{[\mathrm{~mm}]}\end{array}$ & $\begin{array}{c}t_{f} \\
{[\mathrm{~mm}]}\end{array}$ \\
\hline Initial: & 5.00 & 14.0 & 8.0 & 360.0 & 300.0 & 180.0 & 1000.0 & 14.0 & 250.0 & 12.0 \\
Case 9: & 5.00 & 14.1 & 5.0 & 381.6 & 300.6 & 186.6 & 1006.0 & 13.1 & 241.4 & 6.3 \\
\hline \hline
\end{tabular}




\section{List of Figures}

1 Flowchart of the optimization framework . . . . . . . . . . . . . 34

2 Schematic overview of multi-scale model with main dimensions, terminology of sub-levels, and indication of displacement field boundaries (dashed edges) . . . . . 35

3 Detail levels of local model with respectively the major orthotropic shell/beam elements (general mesh size: $h_{c}=1 \mathrm{~m}$ ) and minor detailed shell part (general mesh size: $\left.h_{f}=0.1 \mathrm{~m}\right) \ldots \ldots \ldots \ldots \ldots$

4 Terminology of an orthotropic deck . . . . . . . . . . . . 37

5 Design variables . . . . . . . . . . . . . . . . 38

6 Fatigue details and stress directions . . . . . . . . . . . . . . . 39

$7 \quad 5 \mathrm{~A}-\mathrm{H}$ truck configuration with indication of axle loads $\ldots \ldots$. . . . . . . . 40

8 Position of truck axles for the four load cases on the detailed shell part, with indication of fixed point . . . . . . . . . . . . . . 41

$9 \quad$ Mesh around fatigue detail FD1 (Stress field: von Mises stresses from LC1 [Pa]) . 42

10 Mesh around fatigue detail FD3 (Stress field: transverse direct stresses from LC6

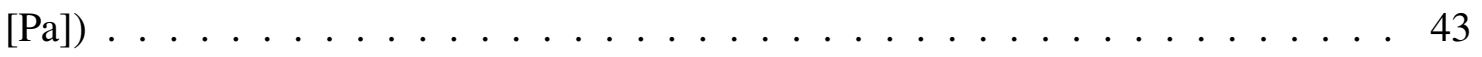

11 Mesh around fatigue detail FD4 (Stress field: longitudinal direct stresses from LC7

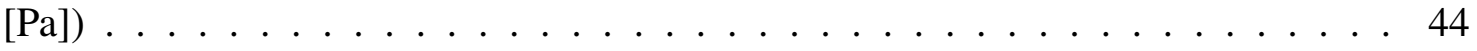

12 Illustration of deflection criterion (vertical deflection field $[\mathrm{m}]) \ldots . . . . . . .45$

13 Optimization results for Case 1 with one design variable . . . . . . . . . 46

14 Optimization results for Case 2 with five design variables . . . . . . . . . . . . 47

15 Optimization results for Case 3 with ten design variables . . . . . . . . . . . 48

16 Girder weight as function of lower bounds on plate thicknesses, respectively with and without the EN stiff. req. . . . . . . . . . . . . . . . . . 49 


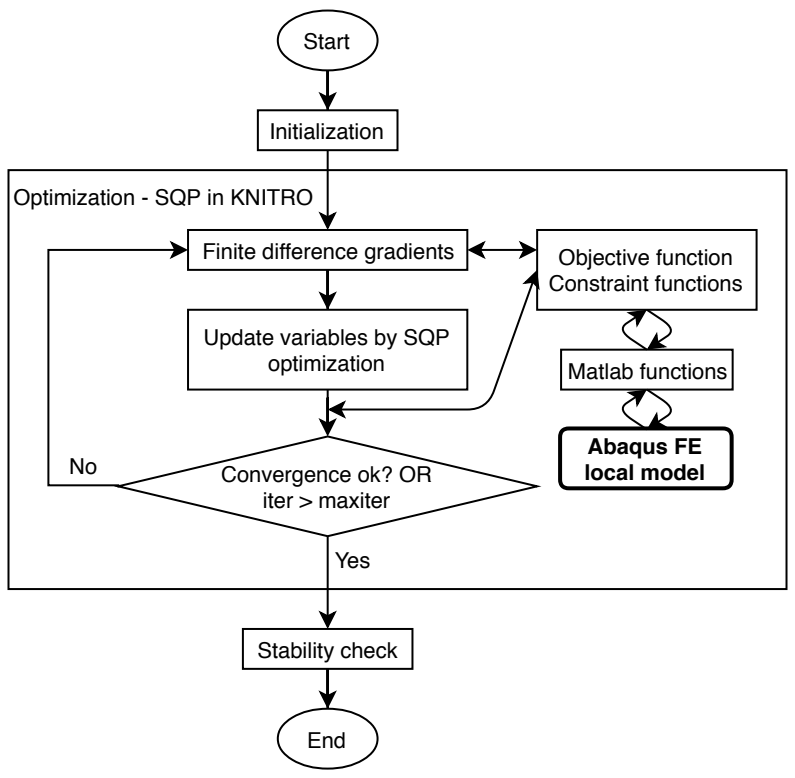

Fig. 1. Flowchart of the optimization framework 


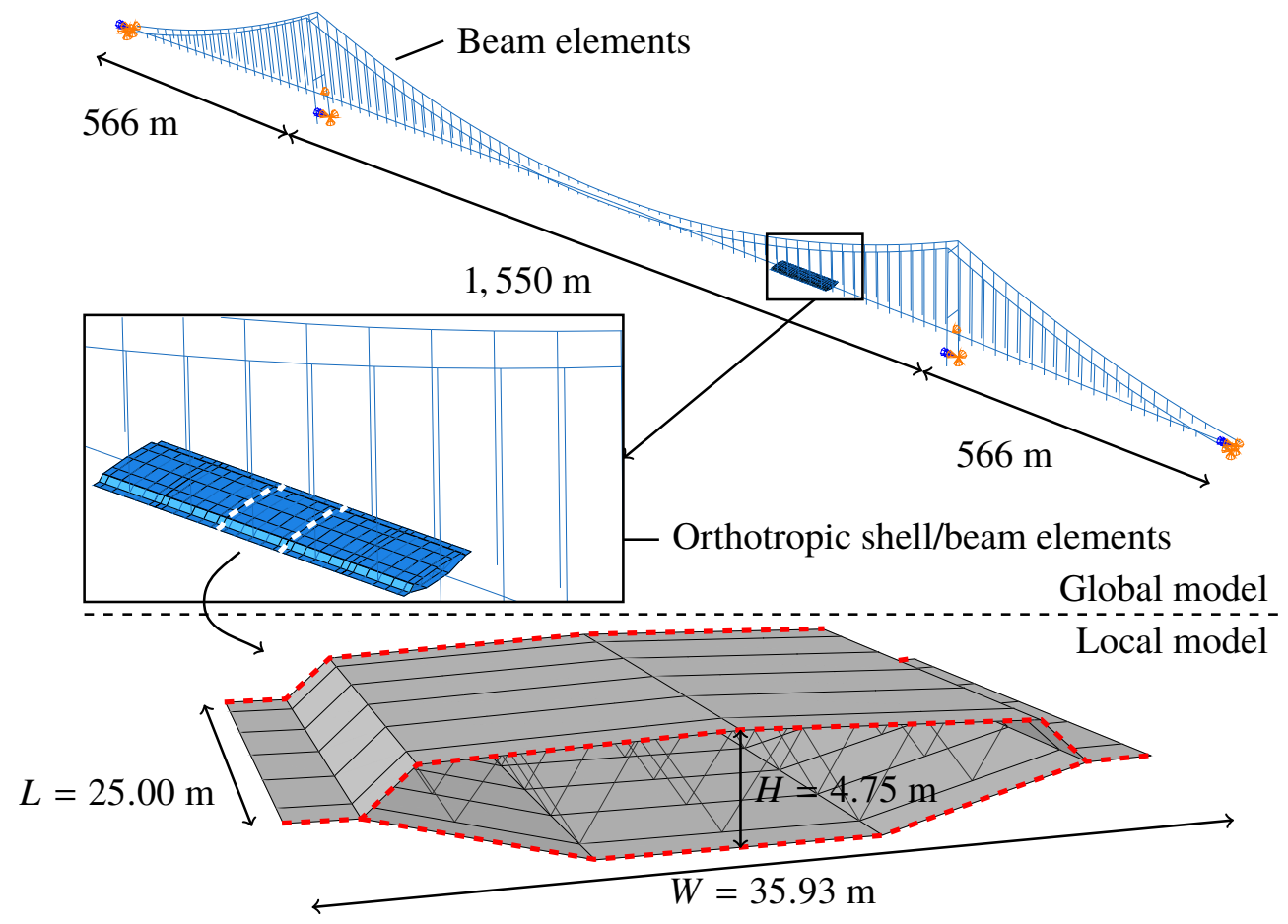

Fig. 2. Schematic overview of multi-scale model with main dimensions, terminology of sub-levels, and indication of displacement field boundaries (dashed edges) 


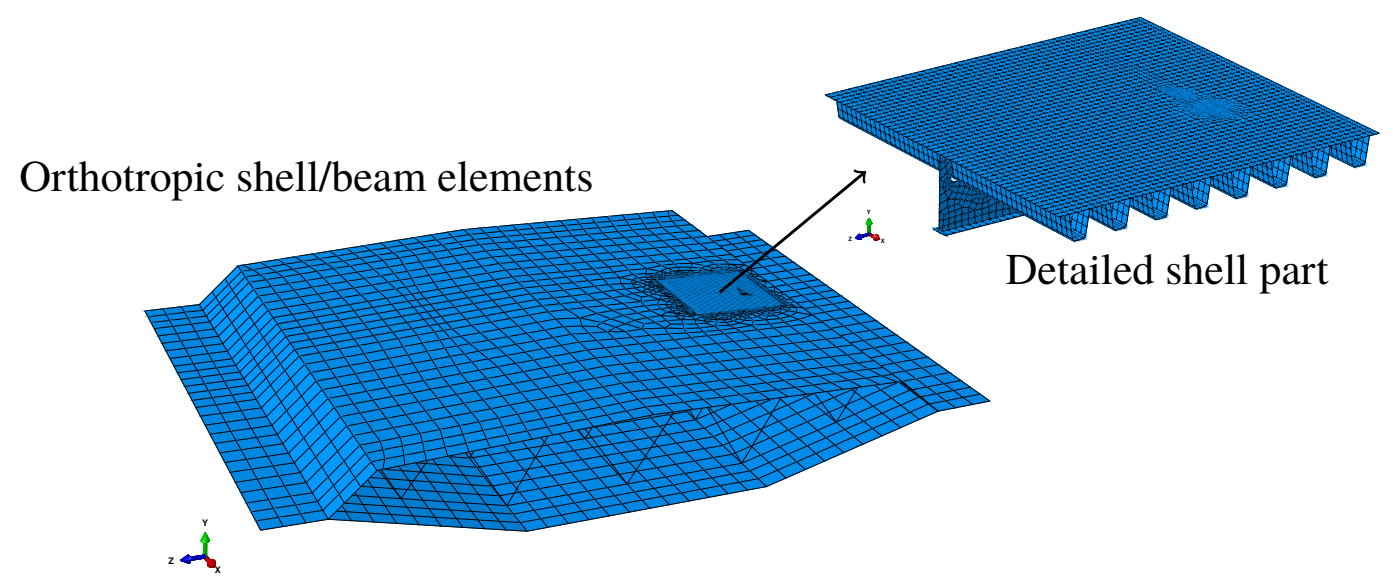

Fig. 3. Detail levels of local model with respectively the major orthotropic shell/beam elements (general mesh size: $h_{c}=1 \mathrm{~m}$ ) and minor detailed shell part (general mesh size: $h_{f}=0.1 \mathrm{~m}$ ) 


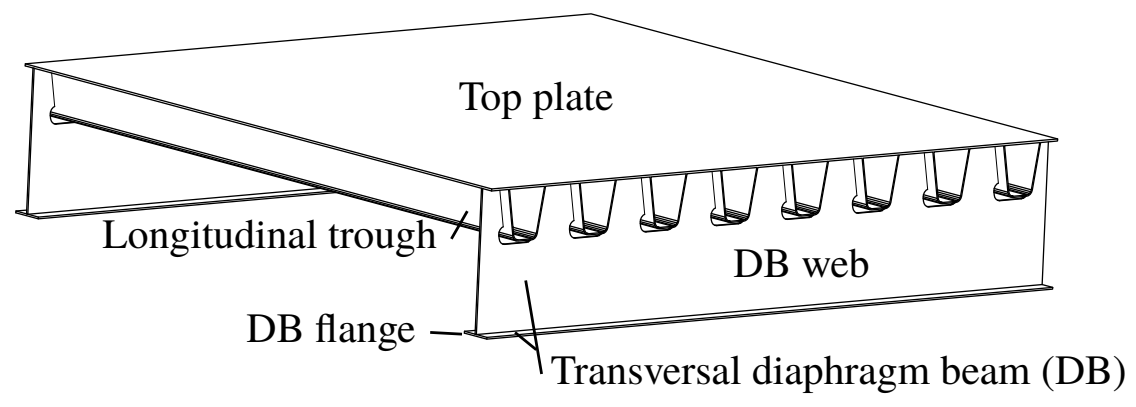

Fig. 4. Terminology of an orthotropic deck 


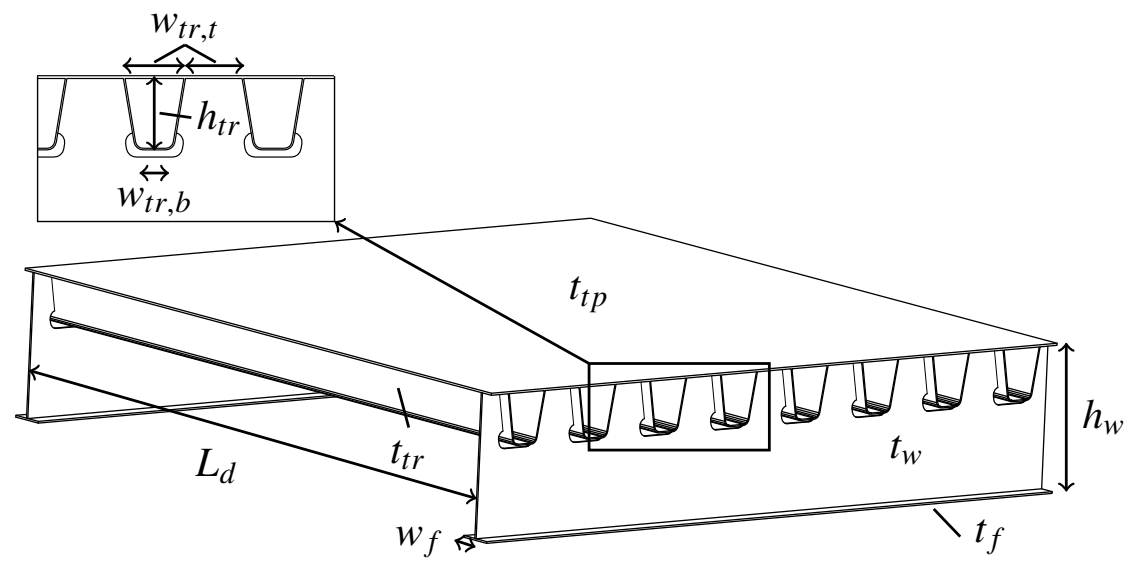

Fig. 5. Design variables 


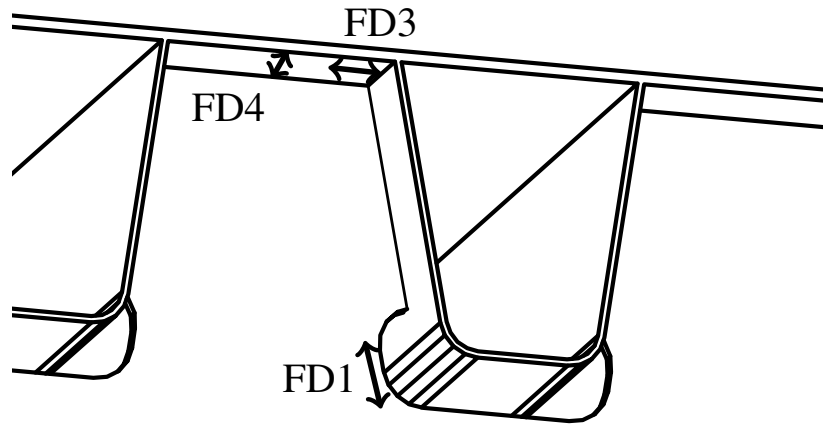

Fig. 6. Fatigue details and stress directions 


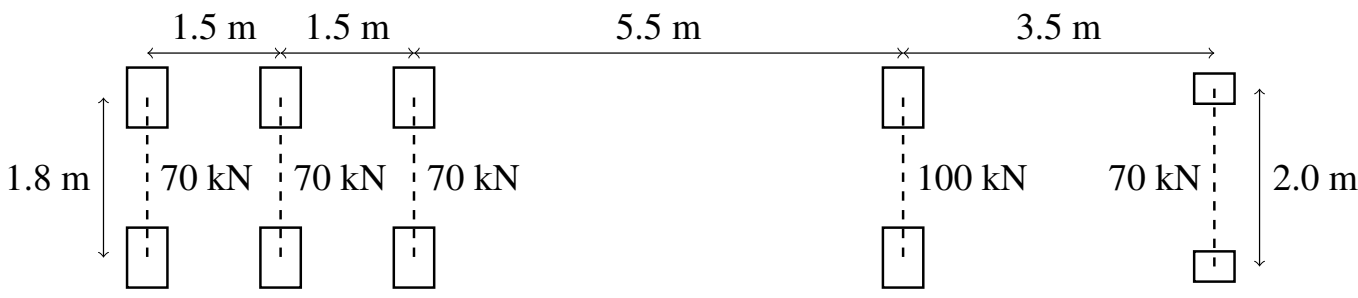

Fig. 7. 5A-H truck configuration with indication of axle loads 


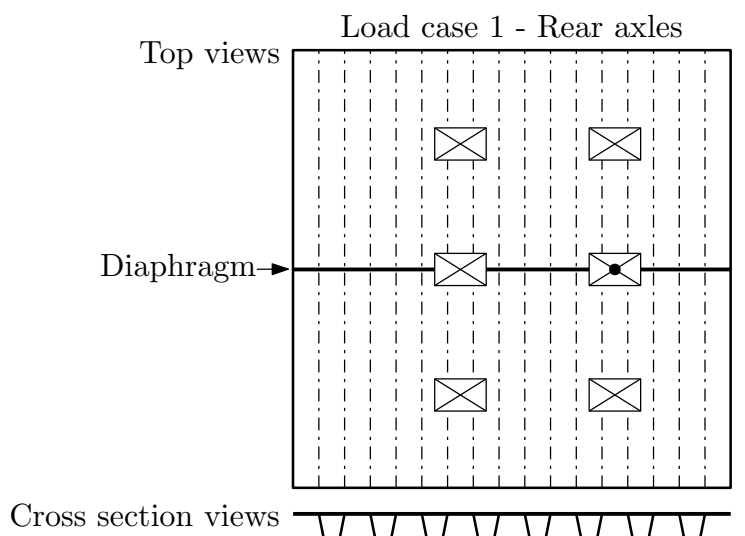

Load case 5 - First axle

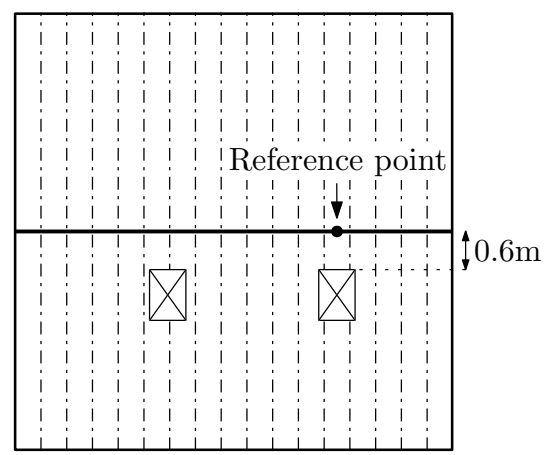

एणणएणणण
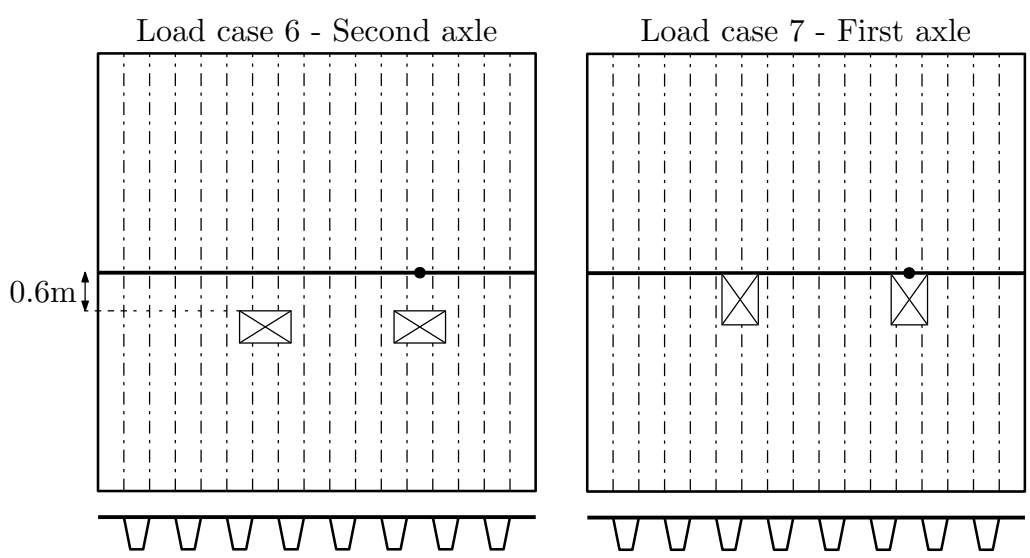

Fig. 8. Position of truck axles for the four load cases on the detailed shell part, with indication of fixed point 


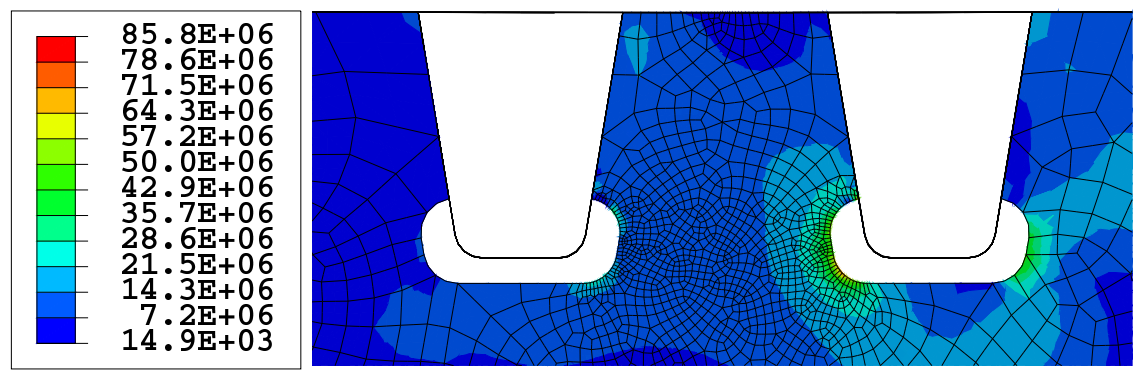

Fig. 9. Mesh around fatigue detail FD1 (Stress field: von Mises stresses from LC1 [Pa]) 


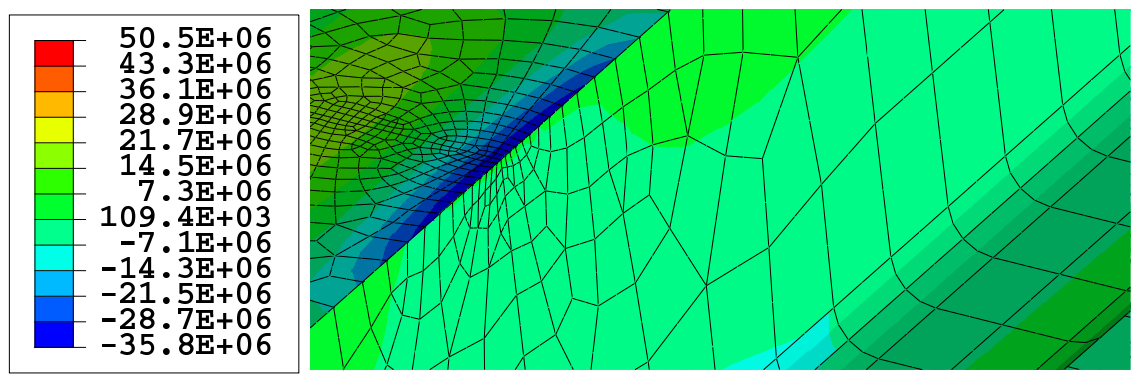

Fig. 10. Mesh around fatigue detail FD3 (Stress field: transverse direct stresses from LC6 [Pa]) 


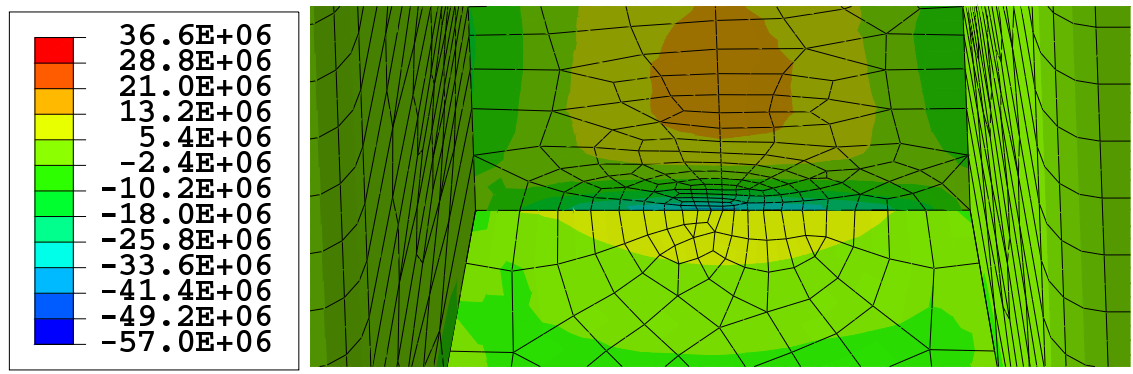

Fig. 11. Mesh around fatigue detail FD4 (Stress field: longitudinal direct stresses from LC7 [Pa]) 


\begin{tabular}{|c|}
\hline $\begin{array}{l}-0.048 \\
-0.049 \\
-0.050 \\
-0.051 \\
-0.052 \\
-0.053 \\
-0.054 \\
-0.055 \\
-0.056 \\
-0.057 \\
-0.058 \\
-0.059 \\
-0.060\end{array}$ \\
\hline
\end{tabular}

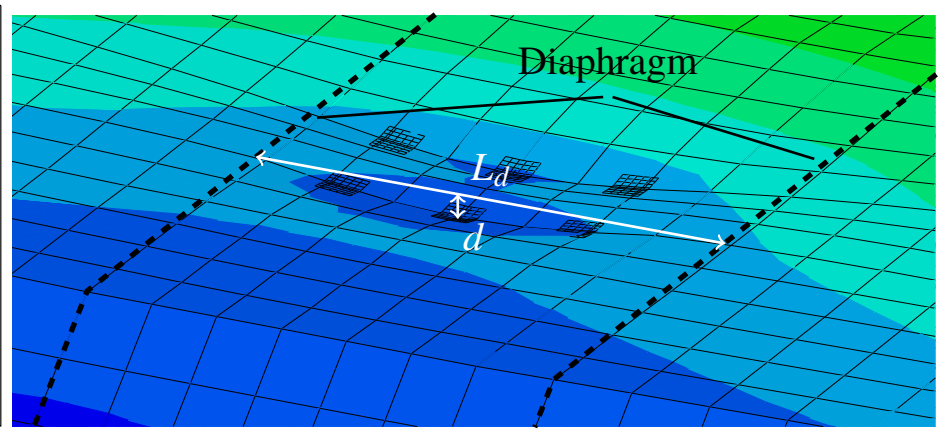

Fig. 12. Illustration of deflection criterion (vertical deflection field [m]) 

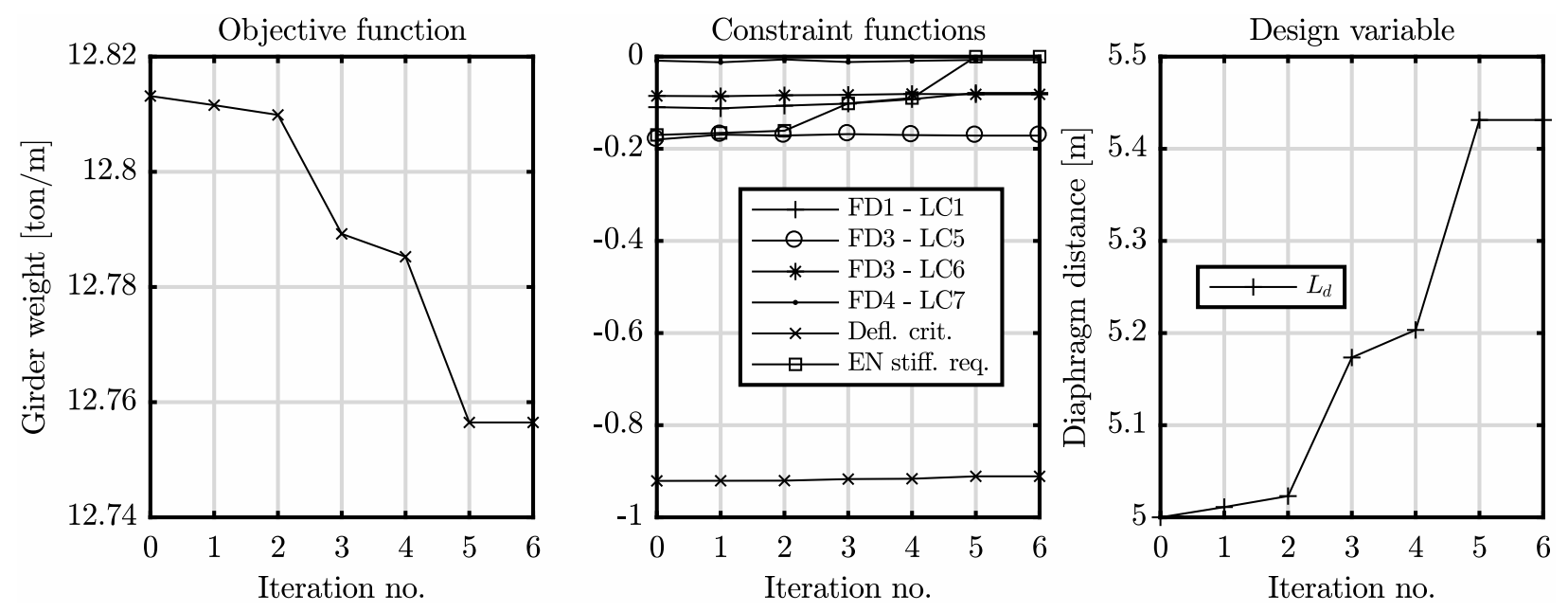

Fig. 13. Optimization results for Case 1 with one design variable 

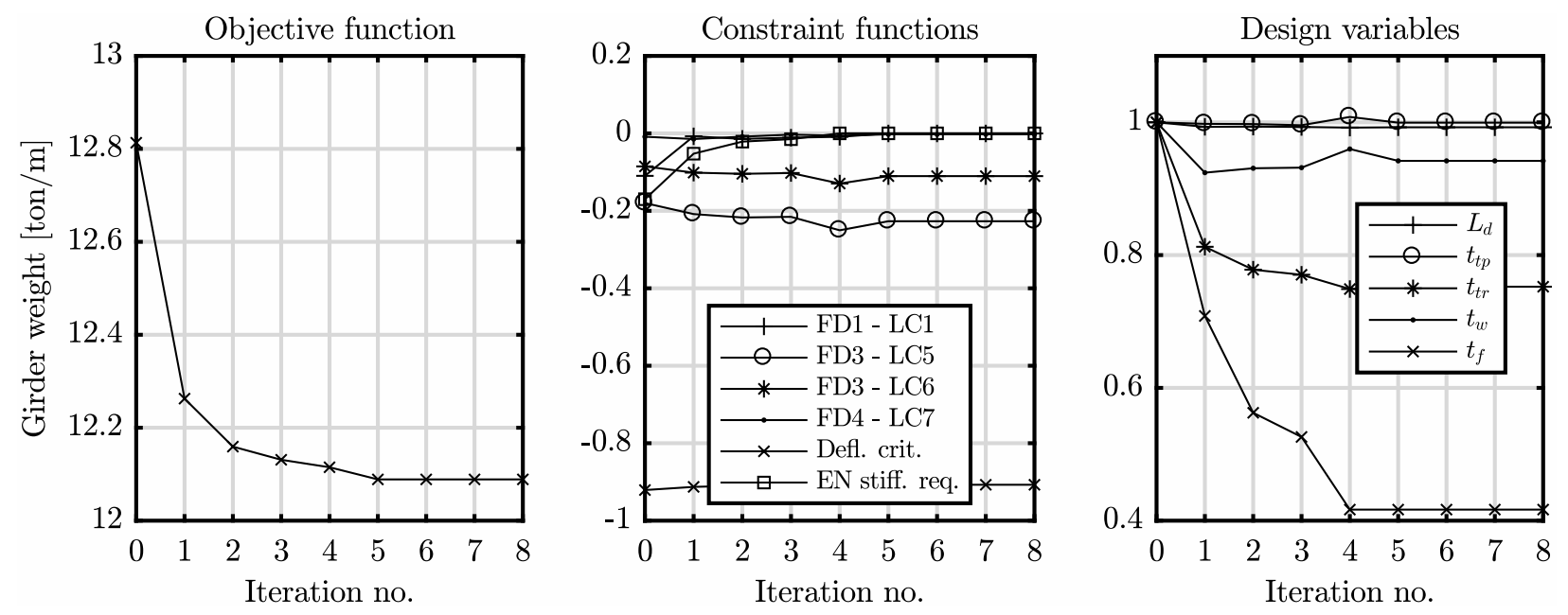

Fig. 14. Optimization results for Case 2 with five design variables 

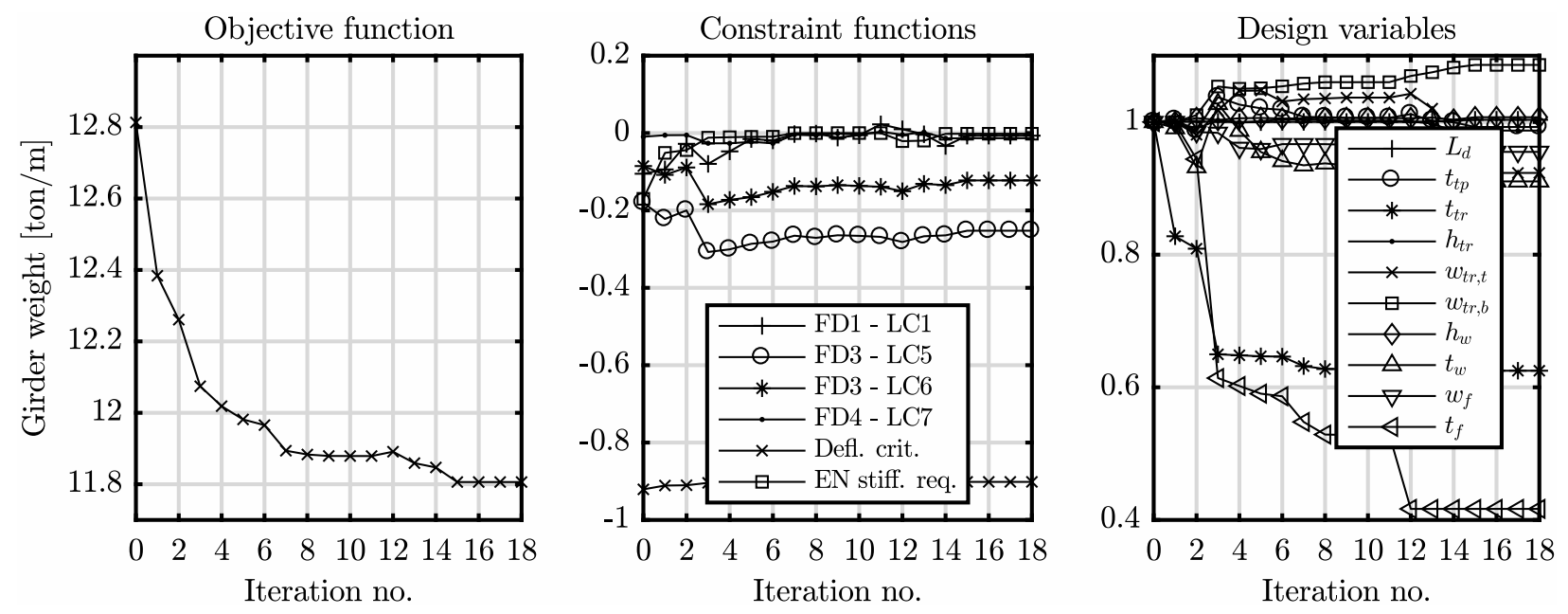

Fig. 15. Optimization results for Case 3 with ten design variables 


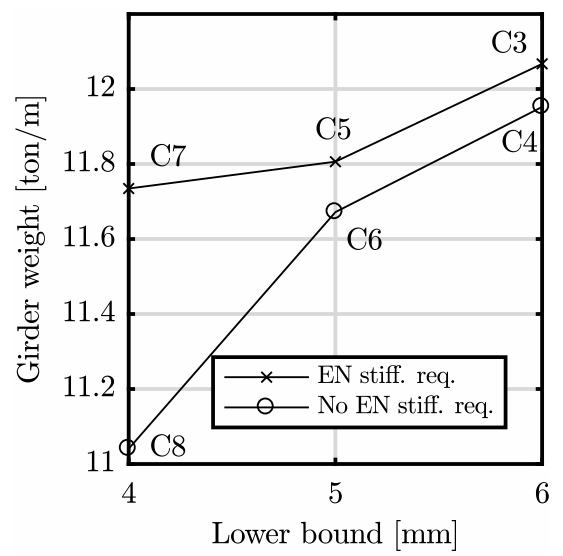

Fig. 16. Girder weight as function of lower bounds on plate thicknesses, respectively with and without the EN stiff. req. 